\title{
Advances in the Management of Paediatric Cushing's Disease
}

\author{
Martin O. Savage Li F. Chan Farhad Afshar P. Nicholas Plowman \\ Ashley B. Grossman Helen L. Storr \\ Departments of Endocrinology, Neurosurgery and Radiotherapy, Barts and the London School of \\ Medicine and Dentistry, London, UK
}

\section{Key Words}

Cushing's disease • Paediatrics • Transsphenoidal surgery •

Pituitary radiotherapy

\begin{abstract}
Cushing's disease (CD) is rare in the paediatric age range, but may present a difficult therapeutic challenge. Most paediatric endocrinologists have limited experience managing children or adolescents with $C D$ and thus benefit from close consultation with adult colleagues. Prior to definitive treatment, a diagnostic protocol for investigation is required which broadly follows the model for adult patients. Treatment strategies for CD are described and critically appraised. The management of paediatric CD patients after cure also presents challenges for optimizing growth, bone health, reproduction and body composition from childhood into and during adult life.

Copyright $\odot 2008$ S. Karger AG, Base
\end{abstract}

\section{Introduction}

Cushing's disease (CD) in childhood and adolescence is very rare, compared to the more common endocrine pathologies such as disorders of growth, puberty and thyroid which make up the major part of paediatric endocrine practice. CD is caused by an ACTH-secreting pituitary adenoma and is the commonest cause of Cushing's syndrome (CS) in children over 5 years of age [1-3].

\section{KARGER}

Fax +41613061234 E-Mail karger@karger.ch www.karger.com
(C) 2008 S. Karger AG, Basel

0301-0163/08/0696-0327\$24.50/0

Accessible online at:

www.karger.com/hre
Some aspects of paediatric CD differ from those present in adults. Examples are the increased frequency in prepubertal males compared to females, the frequent absence of radiological evidence of a corticotroph adenoma on pituitary scanning, the higher incidence of lateralisation of ACTH secretion demonstrated by inferior petrosal sinus sampling (IPSS) and the more rapid response to external beam pituitary radiotherapy. These, together with other aspects of therapy for paediatric CD, will be discussed.

A further theme of the article will be to emphasise that very few, if any, paediatric endocrinology units have sufficient experience to manage $\mathrm{CD}$ in isolation and that consultation and joint decision-making with more experienced adult endocrinology units will be beneficial to the care of the patient.

\section{Diagnostic Aspects of Paediatric Cushing's Disease}

\section{Epidemiology}

The peak incidence of paediatric CD occurs during the adolescent or preadolescent years with median age of presentation in 182 cases taken from the literature being 14.1 years (fig. 1). The youngest child in our own series of 32 cases was aged 6.2 years at diagnosis. Whereas in adults, CD comprises $49-71 \%$ of CS cases, in paediatrics it accounts for $75-80 \%$ of cases $[1,4]$. Paediatric CD is almost always caused by a pituitary microadenoma [5]. We have seen only one macroadenoma out of 32 paediat-

Prof. Martin Savage, Department of Endocrinology

Barts and the London School of Medicine and Dentistry

John Vane Science Centre, Charterhouse Square

London EC1M 6BQ (UK)

Tel. +44 207882 6233, Fax +44 7882 6234, E-Mail m.o.savage@qmul.ac.uk 
Fig. 1. Differing aetiologies of paediatric Cushing's syndrome from the literature $(n=398$ cases $)$ shown at ages of peak incidence.

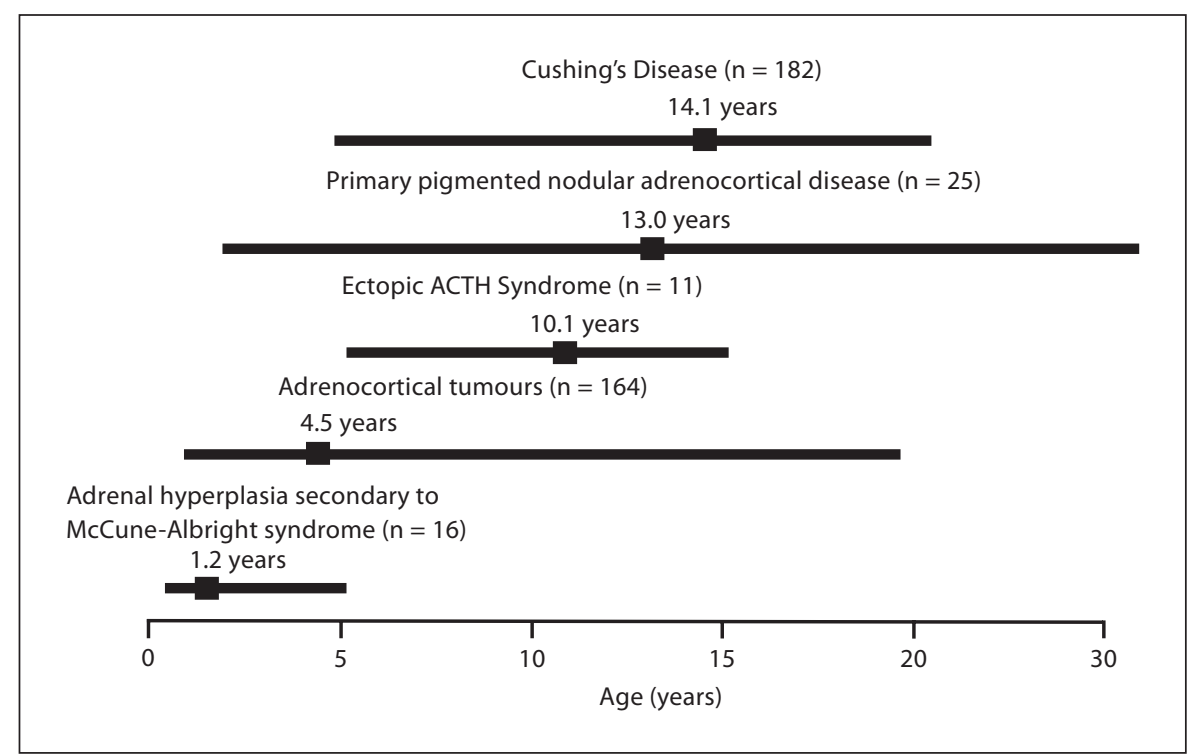

ric cases [6]. However, very rarely this has been reported [7] and may even invade the cavernous sinus [8]. Pituitary macroadenoma has also been described as an early manifestation of MEN1 [9].

In adults, $\mathrm{CD}$ has a female preponderance [10]. Until recently, no comment had been made about sex distribution in children $[12,13]$. We analysed sex at diagnosis in $50 \mathrm{CD}$ patients aged from 6 to 30 years and found a significant predominance of males in the prepubertal patients [14]. There were similar incidences of males and females during puberty and an increasing predominance of females in the post-pubertal patients. Our report was the first to describe this male predominance in young patients; however, examination of cases in the large series from the NIH [3] reveals the same phenomenon. No clear explanation for this exists, although it is tempting to suggest that the oestrogenic milieu during female puberty may be related to the relative increase in females with $\mathrm{CD}$ during and following adolescence.

\section{Key Clinical Diagnostic Features}

The recognition of features which can alert the clinician to the diagnosis of CD is of crucial importance in early diagnosis and treatment. Most children and adolescents have a typical cushingoid appearance. A subtle or subclinical presentation or even cyclical features are uncommon. However, parents and general practitioners frequently fail to recognise the pathological nature of the change in the child's appearance. In $32 \mathrm{CD}$ patients who we have managed, the mean length of symptoms prior to diagnosis was 2.5 years (range 0.5-6.6). Facial appearance was always changed and $100 \%$ of our patients complained of weight gain. Striae were present in $53 \%$ of our patients, being more frequent in the older patients. It was not unusual for a young child with CD to present with obesity and poor growth, but without the classical features of plethora, hirsutism, acne and striae. Additional features were hypertension (47\%), emotional lability (53\%) and fatigue (59\%). Muscle weakness and easy bruising were rare.

\section{Growth and Puberty}

Short stature (height $<-2.0$ SD) was present in $40 \%$ of our patients and growth velocity when available was subnormal. One of the most striking features was the contrast between height SDS, being almost always below the mean, and BMI SDS being consistently above it (fig. 2), as has been previously reported [1]. We compared height and BMI SDS values in 29 patients with CD and 44 agematched patients with simple obesity and showed a significant difference in the ratio of these two variables between the two groups [15], height being increased in simple obesity and decreased in CD. Bone age (BA) at diagnosis in 17 of our $\mathrm{CD}$ patients was delayed in 15 (mean delay 2.0 years; range -0.5 to 4.1 ) and correlated negatively with height SDS $(\mathrm{r}=-0.70 ; \mathrm{p}<0.01)$, duration of symptoms $(\mathrm{r}=-0.48 ; \mathrm{p}=0.05)$ and age at diagnosis $(r=-0.48 ; p=0.05)[16]$.

There are few reports of pubertal development in CD, although it is recognised that virilisation with pseudo- 
Table 1. Scheme of investigation for patients with suspected Cushing's syndrome

Confirmation or exclusion of Cushing's syndrome

1 Urinary-free cortisol excretion (24-hour urine collection) daily $\times 3$

2 Serum cortisol circadian rhythm study (09:00, 18:00 h, midnight [sleeping])

3 Low-dose dexamethasone suppression test (LDDST)

- Dose: 0.5 mg 6-hourly [09:00, 15:00, 21:00, 03:00 h] $\times 48 \mathrm{~h}$

- Dose for patients weighing <40 kg: $30 \mu \mathrm{g} / \mathrm{kg} /$ day

- Serum cortisol measured at 0 and $48 \mathrm{~h}$

Definition of aetiology of Cushing's syndrome

1 Plasma ACTH (09:00 h)

2 CRH test $(1.0 \mu \mathrm{g} / \mathrm{kg}$ i.v. $)$

3 Analysis of change in serum cortisol during LDDST

4 Adrenal or pituitary MRI scan

5 Bilateral inferior petrosal sinus sampling for $\mathrm{ACTH}$ (with CRH) precocious puberty frequently occurs $[1,3]$. We analysed pubertal development in 27 patients and identified abnormal virilisation, defined as unusual advance of Tanner pubic hair stage compared to testicular volume or breast development in 12 [17]. Values of serum androstenedione, DHEAS, as previously reported [18], and testosterone SDS were higher $(\mathrm{p}=0.03,0.008,0.03$, respectively) than in subjects without abnormal virilisation and SHBG SDS values were lower $(\mathrm{p}=0.006)$. Gonadotrophin levels were subnormal in the patients who had commenced true puberty suggesting a suppressive effect of chronic hypercortisolaemia.

\section{Investigations Leading to Definitive Treatment}

\section{Biochemical Confirmation of Cushing's Disease}

In patients suspected of having $\mathrm{CD}$, we routinely perform measurement of basal plasma ACTH. In all of our patients with $\mathrm{CD}(\mathrm{n}=32)$, ACTH was detectable, ranging from 12 to $128 \mathrm{ng} / \mathrm{l}$ (NR 10-50 ng/l). We also perform a $\mathrm{CRH}$ test $(1 \mu \mathrm{g} / \mathrm{kg}$ i.v. $)$ and in $27 \mathrm{CD}$ patients serum cortisol increased by $>20 \%$ (range 106-554\%) [21]. Although it is arguable that ectopic ACTH syndrome is so rare in children that the CRH test is not justified, we find an increased cortisol response contributes to the diagnosis of $\mathrm{CD}$. We no longer perform a routine high-dose dexamethasone suppression test (HDDST). This recent decision follows an analysis of serum cortisol suppression

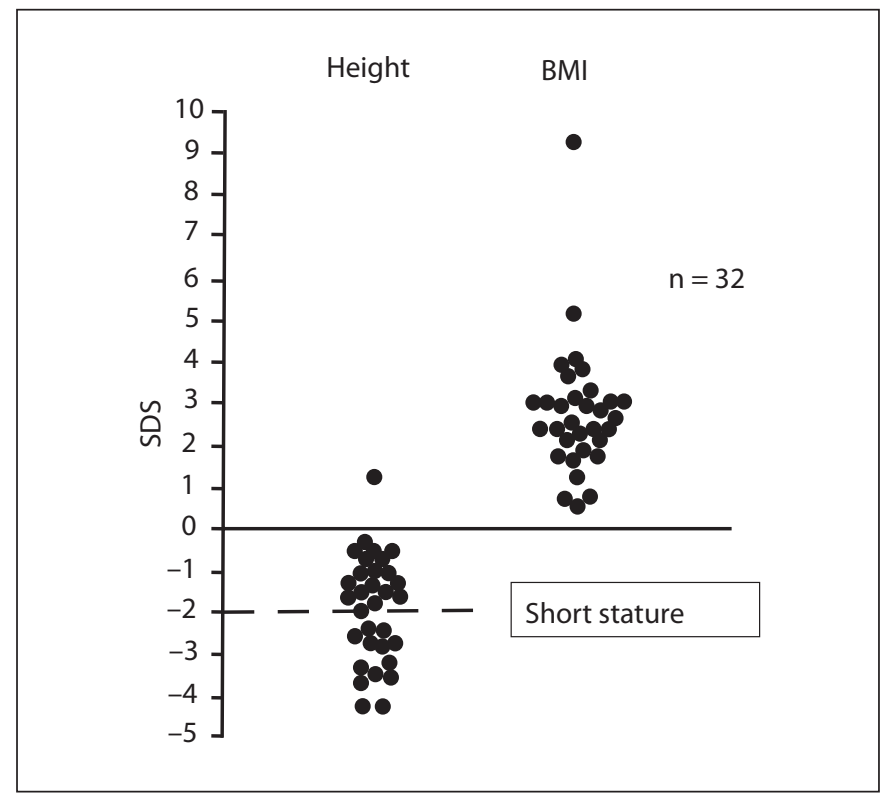

Fig. 2. Height and body mass index (BMI) SDS values in 32 paediatric patients with Cushing's disease.

during low-dose dexamethasone suppression test (LDDST) and HDDST. In adult patients with ACTH-dependent CS, the change in cortisol during LDDST has been shown to distinguish between pituitary and ectopic ACTH secretion, questioning the value of the HDDST [22].

We have now reported similar findings in children [23]. In 24 patients with $C D$, mean baseline serum cortisol values of $590.7 \pm 168.8 \mathrm{nmol} / \mathrm{l}$ decreased to $337.4 \pm$ $104.0 \mathrm{nmol} / \mathrm{l}$ at $48 \mathrm{~h}$ during LDDST ( $\mathrm{p}<0.05$; mean decrease, $45.1 \%$ ) with $66 \%$ decreasing by $>30 \%$. Cortisol suppression during LDDST correlated with that during HDDST $(r=+0.45, p<0.05)$. Consequently, decrease of cortisol during the LDDST strongly supports the diagnosis of CD (table 1).

\section{Radiological Investigations}

Pituitary imaging using MRI is an important step towards the successful treatment of CD by transsphenoidal surgery (TSS). As previously mentioned, most paediatric ACTH-secreting pituitary tumours are microadenomas with a diameter $<5 \mathrm{~mm}$ [5]. The majority of these have a hypointense signal on MRI, which fails to enhance with gadolinium [19]. In the large NIH series, approximately 


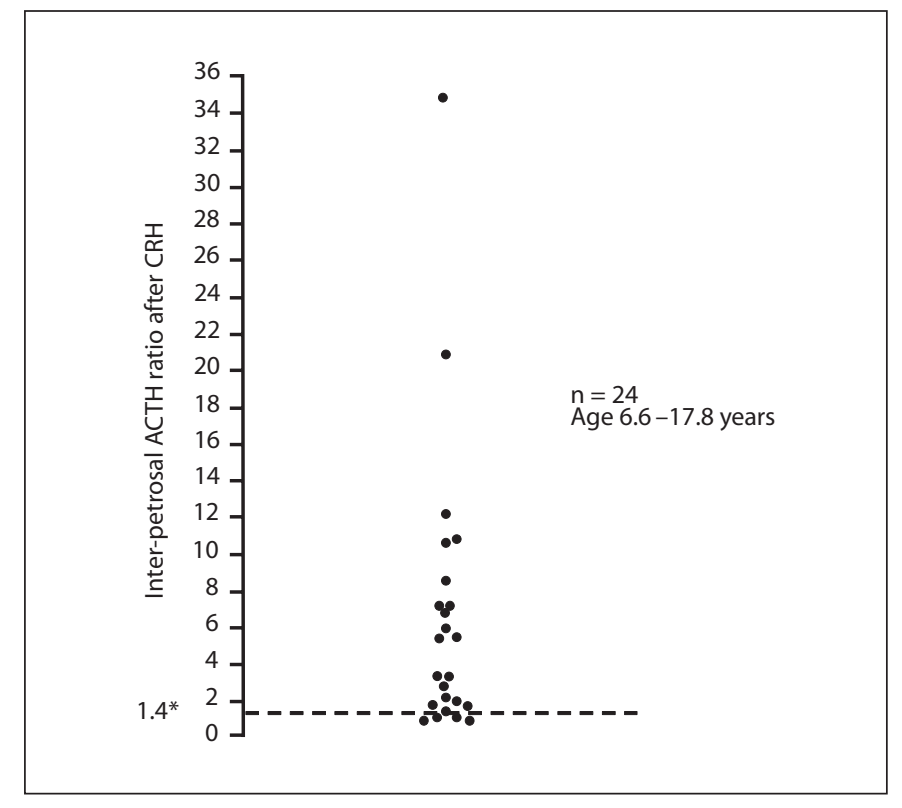

Fig. 3. Inter-petrosal ACTH ratio during bilateral inferior petrosal sinus sampling in paediatric patients with Cushing's disease. * Ratio of $\geq 1.4$ indicates lateralisation of ACTH secretion, 19/23 (83\%) showed lateralisation of ACTH secretion.

$50 \%$ of microadenomas were visible on pituitary MRI [3]. In our series, pituitary imaging was relatively unhelpful, showing a normal appearance in over half of the patients, with a low predictive value of the position of the adenoma, as identified at surgery (table 2) [6].

\section{Bilateral Inferior Petrosal Sinus Sampling for ACTH (BIPSS)}

The technique of BIPSS was developed mainly at the $\mathrm{NIH}$ during the 1980s [24] and has become routine in adult practice. It was hoped that BIPSS would distinguish $\mathrm{CD}$ from ectopic ACTH syndrome and also provide a method of identifying a lateral or central source of pituitary ACTH secretion [19]. In children, because of the extreme rarity of ectopic ACTH syndrome, the aim of BIPSS is primarily to demonstrate possible lateralisation of ACTH secretion. The first paediatric data were reported in the large NIH series [3] where a predictive value of lateralisation was $75-80 \%$ [1]. We have been performing BIPSS in paediatric patients since 1987 and previously reported our experience, suggesting that ACTH sampling gave a better prediction of the site of the microadenoma than pituitary imaging [25].
Table 2. Pituitary imaging, surgical identification of adenoma and cure by TSS

\begin{tabular}{llll}
\hline $\begin{array}{l}\text { Total patients } \\
\mathrm{n}\end{array}$ & $\begin{array}{l}\text { Adenoma CT/ } \\
\text { MRI image, } \mathrm{n}\end{array}$ & $\begin{array}{l}\text { Concordance of } \\
\text { image with surgery, } \mathrm{n}\end{array}$ & $\begin{array}{l}\text { Cure by } \\
\text { TSS, } \mathrm{n}\end{array}$ \\
\hline 31 & $17(55 \%)$ & $9(52 \%)$ & $20(64 \%)$
\end{tabular}

$\mathrm{n}=$ Number of patients; MRI = magnetic resonance imaging; $\mathrm{CT}=$ computed tomography imaging; TSS = transsphenoidal selective adenomectomy.

BIPSS is a highly specialised technique and in our unit is performed by the same radiologist who regularly studies adult patients. We do not use general anaesthesia to avoid potential alteration of ACTH secretion. The youngest patient we studied without general anaesthesia was aged 8.4 years. We have now performed BIPSS in 24 paediatric CD patients, without complications, and have shown lateralisation (inter-petrosal sinus ACTH ratio of $>1.4$ after $\mathrm{CRH}$ ) [6] in 79\% of patients (fig. 3). A more recent study from the NIH described experience of BIPSS in 94 paediatric patients and reported that localisation of ACTH secretion concurred with the site of the adenoma at surgery in $58 \%$ of cases, concluding that the technique was not an essential part of a paediatric investigation protocol [26]. The percentage of lateralisation however increased to 70\% (51/73) after exclusion of 18 centrally located and 4 bilateral lesions.

\section{Treatment of Cushing's Disease}

\section{Historical Aspects}

$\mathrm{CD}$ in childhood causes considerable morbidity and requires prompt and expert treatment, which should be curative. The approach to treatment has evolved over the years. Initially bilateral adrenalectomy was widely practised and while effective in lowering hypercortisolaemia, the pituitary adenoma remained in situ, and there was an appreciable risk of post-adrenalectomy Nelson's syndrome $[27,28]$. In the management of 33 cases of $C D$, we have only performed adrenalectomy twice, when the patients were extremely unwell and not fit to undergo pituitary surgery. In 1 of these patients, the hypercortisolaemia was uncontrollable by oral metyrapone and treatment was given with intravenous etomidate which successfully controlled the cortisol levels prior to adrenalectomy [29]. Medical therapy to lower cortisol using 
Table 3. BIPSS results, surgical identification of adenoma and cure by TSS

\begin{tabular}{|c|c|c|c|c|}
\hline \multirow{2}{*}{$\begin{array}{l}\text { Total } \\
\text { patients } \\
\text { n }\end{array}$} & \multicolumn{4}{|c|}{ BIPSS results } \\
\hline & $\begin{array}{l}\text { laterali- } \\
\text { sation, } \mathrm{n}\end{array}$ & $\begin{array}{l}\text { non-laterali- } \\
\text { sation, } \mathrm{n}\end{array}$ & $\begin{array}{l}\text { concordance of BIPSS } \\
\text { result with surgery, } n\end{array}$ & $\begin{array}{l}\text { cure by } \\
\text { TSS, n }\end{array}$ \\
\hline 24 & $19(79 \%)$ & $5(21 \%)$ & $20(83 \%)$ & $18(75 \%)$ \\
\hline
\end{tabular}

$\mathrm{n}=$ Number of patients; BIPSS = bilateral simultaneous inferior petrosal sinus sampling; TSS = transsphenoidal selective adenomectomy.

metyrapone or ketoconazole is a short-term option but cannot be recommended as a long-term definitive therapy for CD.

\section{Transsphenoidal Surgery}

Transsphenoidal surgery (TSS) consisting of selective removal of the adenoma is now considered first-line therapy for paediatric CD. TSS is regarded as a safe and effective procedure in children [30-33]. Adult CD studies show variable surgical success rates depending on which definition of cure is adopted. Our adult endocrine unit has traditionally used the definition of undetectable postoperative serum cortisol $(<50 \mathrm{nmol} / \mathrm{l})$ for successful treatment, i.e. cure [34]. We use the same definition. In adult practice, recurrence of CD following TSS, using this definition of cure, is extremely uncommon [34].

Selective microadenomectomy can be technically very difficult in children. As discussed above, the microadenomas may be very small and an appreciable rate of failure, in terms of definite cure, exists even in the hands of the most experienced neurosurgeons. We have recently analysed our experience over the past 25 years and considered the factors which contributed to successful surgical therapy [6]. The overall cure rate from TSS in 31 paediatric patients treated from 1982 to 2007 was $64 \%$ and in 25 of these patients, treated since routine IPSS was introduced as pre-operative preparation, the cure rate was $75 \%$ (table 3). We therefore feel that the ability of IPSS to correctly identify the lateral or central position of the adenoma has contributed to an increased rate of surgical success [44]. Other paediatric series report cure rates varying from 45 to $78 \%$ [12, 13, 35, 36], but very few report rates of $>90 \%[3,5]$.

Successful selective adenomectomy consists of retaining normal pituitary tissue, which is key to the child's development and quality of life. Following complete sur- gical removal of the microadenoma, the patient has adrenal insufficiency because of lack of function of normal corticotrophs. In all of our cured patients, repeated undetectable values of cortisol were recorded during the 1month period following TSS. Hydrocortisone replacement is therefore required, which should be given in physiological doses. Recovery of the pituitary adrenal axis may take many months and is detected by careful withdrawal of hydrocortisone followed by demonstration of endogenous cortisol secretion in a day curve reaching a mean value of $\sim 150 \mathrm{nmol} / \mathrm{l}$. Post-operative hypopituitarism is therefore a potential complication of TSS; however, low rates have been reported in several large series $[31,35]$. An important potential hormone deficiency for future growth is that of growth hormone $(\mathrm{GH})$ which will be discussed below.

\section{Pituitary Radiotherapy}

Pituitary radiotherapy (RT) has been considered a therapeutic option for paediatric CD for many years. Children with $\mathrm{CD}$ have been shown to respond more rapidly than adults $[37,38]$. In our centre, external beam RT is used as second-line therapy, following unsuccessful TSS. Our practice is to make a decision to proceed to RT, usually within 2-4 weeks of TSS, when it is clear from circulating cortisol levels that complete removal of the adenoma has not been achieved [39]. The RT protocol we follow consists of delivering 45 Gy in 25 fractions over 35 days [40]. We have treated 12 patients during the past 25 years with a successful cure rate of $92 \%$, which occurred at a mean interval of 0.83 years (range $0.13-2.86$ ) following completion of therapy. We have recently analysed long-term pituitary function in 6 of these patients and have shown that although GH deficiency was frequent initially, some recovery may occur [41]. Gonadotrophin secretion was generally preserved with normal, or early [42] puberty, and TSH and ACTH deficiency was minimal. We have not studied cognitive function following pituitary RT. However, we know of no data demonstrating a decrease in IQ related to targeted pituitary RT, as opposed to therapy using a broader field as for paediatric brain tumours.

\section{Post-Cure Growth and Development}

Most patients with paediatric CD have subnormal growth rates and short stature at diagnosis $[1,43]$. The challenge is to reverse these problems so as to achieve acceptable adult height and body composition. A key article from the NIH described the abnormalities of height and $\mathrm{GH}$ secretion [44] together with a rather pessimistic view 
of post-treatment catch-up growth and adult height [45]. We have also documented disappointing post-cure catchup, which we attribute to continuing GH deficiency, occurring either from TSS, pituitary RT or the long-standing effects of chronic hypercortisolaemia on pituitary and growth plate physiology [43].

Our approach now is to test for GH deficiency 3 months after TSS or completion of RT. If GH therapy is demonstrated, we start therapy in a standard GH dose of 0.025 $\mathrm{mg} / \mathrm{kg} /$ day. GnRH analogue therapy may be added to delay puberty and epiphyseal closure. Results demonstrate that catch-up growth usually occurs and adult height within range of target height is achieved for the majority of patients [46]. GH deficiency may persist for many years [47] but in the adult follow-up patients was usually not severe enough to indicate GH replacement as recommended for the adult GH deficiency syndrome.

Normal body composition is more difficult to achieve. Many patients remain obese and BMI SDS was elevated $(\mathrm{p}<0.01)$ at a mean interval of 3.9 years after cure in 14 patients [46]. A long-term follow-up study of childhood and adolescent CD showed that total body fat and the ratio of visceral to subcutaneous fat was abnormally high in the majority of patients studied 7 years after cure [48]. The implications of chronic excess visceral fat in terms of risk for adult metabolic syndrome deserve future study. Bone mineral density was closer to normal, a finding which we also reported, together with some patients having normal bone mineral density at diagnosis [49].

\section{Conclusion}

Paediatric CD contains a number of features which characterise this age range. Delay in diagnosis is frequent because of the lack of appreciation of the nature of the pathology by parents and general practitioners. Once suspected, CD should be diagnosed using a formal investigation protocol. The choice and interpretation of tests is most productively discussed with an adult specialist with experience of CD. Effective and curative therapy requires a multidisciplinary approach and referral should be considered to a centre combining paediatric and adult endocrinology, TSS and pituitary RT. The choice of neurosurgeon experienced in TSS in children is likely to significantly improve the chance of cure. Whereas the prognosis for cure is good in the majority of children and adolescents, post-treatment management presents challenges for optimization of growth, puberty and body composition.

\section{References}

1 Magiakou MA, Chrousos GP: Cushing's syndrome in children and adolescents: current diagnostic and therapeutic strategies. J Endocrinol Invest 2002;25:181-194.

-2 Savage MO, Besser GM: Cushing's disease in childhood. Trends Endocrinol Metab 1996; 7:213-216.

3 Magiakou MA, et al: Cushing's syndrome in children and adolescents. Presentation, diagnosis and therapy. N Engl J Med 1994;331: 629-636.

$\checkmark 4$ Weber A, et al: Investigation, management and therapeutic outcome in 12 cases of childhood and adolescent Cushing's syndrome. Clin Endocrinol 1995;43:19-28.

5 Fahlbusch R, et al: Neurosurgical management of Cushing's disease in children; in Savage MO, Bourguignon JP, Grossman AB (eds): Frontiers of Paediatric Neuroendocrinology. Oxford, Blackwell Scientific, 1994, pp 68-72.

-6 Storr HL, et al: Factors influencing cure by transsphenoidal selective adenomectomy in paediatric Cushing's disease. Eur J Endocrinol 2005; 152:825-833.

7 Khadilkar VV, et al: Cushing's disease in an 11-month-old child. Indian Pediatr 2004;41: 274-276.
-8 Damiani D, et al: Pituitary macroadenoma and Cushing's disease in pediatric patients: patient report and review of the literature. J Pediatr Endocrinol Metab 1998;11:665-669.

$\checkmark 9$ Stratakis CA, et al: Pituitary macroadenoma in a 5-year-old: an early expression of multiple endocrine neoplasia type 1. J Clin Endocrinol Metab 2000;85:4776-4780.

10 Besser GM, Trainer PJ: Cushing's syndrome; in Besser GM, Thorner MO (eds): Comprehensive Clinical Endocrinology, ed 3. Edinburgh, Mosby, 2002, pp 193-202.

11 Giraldi FP, et al: Gender-related differences in the presentation and course of Cushing's disease. J Clin Endocrinol Metab 2003;80: 3818-3820.

12 Leinung $\mathrm{MC}$, et al: Long-term follow-up of transsphenoidal surgery for the treatment of Cushing's disease in childhood. J Clin Endocrinol Metab 1995;80:2475-2479.

13 Devoe DJ, et al: Long-term outcome in children and adolescents after transsphenoidal surgery for Cushing's disease. J Clin Endocrinol Metab 1997;82:3196-3202.

14 Storr HL, et al: Pre-pubertal Cushing's is more common in males, but there is no increase in severity at diagnosis. J Clin Endocrinol Metab 2004;89:3818-3820.
15 Greening JE, et al: Linear growth and body mass index in paediatric patients with Cushing's disease or simple obesity. J Endocrinol Invest 2006;29:885-887.

16 Peters CJ, et al: Factors influencing skeletal maturation at diagnosis of paediatric Cushing's disease. Horm Res 2007;68:231-235.

$\checkmark 17$ Dupuis C, et al: Abnormal puberty in paediatric Cushing's disease: relationships with adrenal androgens, sex hormone binding globulin and gonadotrophin concentrations. Clin Endocrinol (Oxf) 2007;66:838-843.

18 Hauffa B, et al: Dissociation between plasma adrenal androgens and cortisol in Cushing's disease and ectopic ACTH-producing tumour: elation to adrenarche. Lancet 1984;1: 1373-1376.

19 Newell-Price J, et al: The diagnosis and differential diagnosis of Cushing's and pseudoCushing's syndrome. Endocr Rev 1998;19: 647-672.

20 Arnaldi G, et al: Diagnosis and complications of Cushing's syndrome: a consensus statement. J Clin Endocrinol Metab 2003;88: 5593-5602. 
21 Peters CJ, et al: The role of corticotrophinreleasing hormone in the diagnosis of Cushing's syndrome. Eur J Endocrinol 2006;155: S93-S98.

$\checkmark 22$ Isidori A, et al: Discriminatory value of the low-dose dexamethasone suppression test in establishing the diagnosis and differential diagnosis of Cushing's syndrome. J Clin Endocrinol Metab 2003;88:5299-5306.

$\checkmark 23$ Dias R, et al: The discriminatory value of the low-dose dexamethasone suppression test in the investigation of paediatric Cushing's syndrome. Horm Res 2006;65:159-162.

$\checkmark 24$ Oldfield EH, et al: Petrosal sinus sampling with corticotropin-releasing hormone to distinguish Cushing's disease from pseudoCushing's states or normal physiology. N Engl J Med 1991;325:897-905.

$\checkmark 25$ Lienhardt A, et al: Relative contributions of inferior petrosal sinus sampling and pituitary imaging in the investigation of children and adolescents with ACTH-dependent Cushing's syndrome. J Clin Endocrinol Metab 2001;86:5711-5714.

26 Batista D, et al: An assessment of petrosal sinus sampling for localisation of pituitary microadenomas in children with Cushing disease. J Clin Endocrinol Metab 2006;91: 221-224.

27 Hopwood NJ, Kenny FM: Incidence of Nelson's syndrome after adrenalectomy for Cushing's disease in children: results of a nationwide survey. Am J Dis Child 1977;131: 1353-1356.

28 McArthur RG, et al: Childhood Cushing disease: results of bilateral adrenalectomy. J Pediatr 1979;95:214-219.

-29 Greening JE, et al: Efficient short-term control of hypercortisolaemia by low-dose etomidate in severe paediatric Cushing's syndrome. Horm Res 2005;64:140-143.
30 Massoud AF, et al: Transsphenoidal surgery for pituitary tumours. Arch Dis Child 1997; 76:398-404.

31 Knappe UJ, Ludecke DK: Transnasal microsurgery in children and adolescents with Cushing's disease. Neurosurgery 1996;39: 484-493.

32 Kanter AS, et al: Single-center experience with pediatric Cushing's disease. J Neurosurg 2005;103(5 suppl):413-420.

33 Joshi SM, et al: Cushing's disease in children and adolescents: 20 years of experience in a single neurosurgical centre. Neurosurgery 2005;57:281-285.

34 Trainer PJ, et al: Transsphenoidal resection in Cushing's disease: undetectable serum cortisol as the definition of successful treatment. Clin Endocrinol 1993;56:25-31.

35 Linglart A, Visot A: Cushing's disease in children and adolescents. Neurochirurgie 2002;48:271-280.

36 Styne DM, et al: Treatment of Cushing's syndrome in childhood and adolescence by transsphenoidal microadenomectomy. N Engl J Med 1984;310:889-893.

37 Jennings AS, et al: Results of treating childhood Cushing's disease with pituitary irradiation. N Engl J Med 1977;297:957-962.

38 Thoren M, et al: Treatment of Cushing's disease in childhood and adolescence by stereotactic pituitary irradiation. Acta Paediatr Scand 1986;75:388-395

39 Storr HL, et al: Clinical and endocrine re sponses to pituitary radiotherapy in pediatric Cushing's disease. J Clin Endocrinol Metab 2003;88:34-37.

40 Plowman PN: Pituitary radiotherapy: techniques and potential complications; in Sheaves R, Jenkins PJ, Wass JAH (eds): Clinical Endocrine Oncology. Oxford, Blackwell Scientific, 1997, pp 185-188.
41 Chan L, et al: Long-term anterior pituitary function in patients with paediatric Cushing's disease treated with pituitary radiotherapy. Eur J Endocrinol 2007;156:477482 .

42 Nicholl RM, et al: Acceleration of pubertal development following pituitary radiotherapy for Cushing's disease. Clin Oncol 1993;3: 393-394.

43 Lebrethon M-C, et al: Linear growth and final height after treatment of Cushing's disease in childhood. J Clin Endocrinol Metab 2000;85:3262-3265.

44 Magiakou MA, et al: suppressed spontaneous and stimulated growth hormone secretion in patients with Cushing's disease before and after surgical cure. J Clin Endocrinol Metab 1994;78:131-137.

45 Magiakou MA, et al: Final stature in patients with endogenous Cushing's syndrome. J Clin Endocrinol Metab 1994;79:1082-1085.

46 Davies JH, et al: Final adult height and body mass index after cure of paediatric Cushing's disease. Clin Endocrinol 2005;62:466-472.

$\checkmark 47$ Carroll PV, et al: Successful treatment of childhood-onset Cushing's disease is associated with persistent reduction in growth hormone secretion. Clin Endocrinol 2005; 60:169-174

48 Leong GM, et al: Effects of child- and adolescent-onset endogenous Cushing syndrome on bone mass, body composition and growth: a 7-year prospective study into young adulthood. J Bone Miner Res 2007;22:110-118.

49 Scommegna S, et al: Bone mineral density at diagnosis and following successful treatment of disease. J Endocrinol Invest 2005;28: 231-235. 